EUROPEAN HONORS COUNCIL

Paper

\title{
Promoting talent development in honours: The Honours Experience
}

\author{
Pierre van Eijl ${ }^{1 *}$, Albert Pilot ${ }^{2}$, Vincent Gelink ${ }^{3}$, Ninib Dibo ${ }^{3}$
}

1. Honorary researcher, Utrecht University, The Netherlands, p.j.vaneij|@uu.nl

2. Emeritus professor Utrecht University, The Netherlands, a.pilot@uu.nl

3. Honours alumni Saxion University of Applied Sciences, The Netherlands, vincent.gelink@gmail.com; ninibdibo@hotmail.com

*Corresponding author: p.j.vaneijl@uu.nl

Received: 30 January 2017; Accepted: 29 March 2017; Published: 25 April 2017

Keywords: circle of talent development, honours programme, higher education, meeting challenges, 21st century skills, teacher dilemma

\section{Introduction}

In recent years many honours programmes were introduced at universities and colleges in the Netherlands (Van Eijl, Pilot \& Wolfensberger, 2010). An important goal of these programmes is to stimulate students to more fully develop their talents. To get more insight in the process of talent development from the perspective of honours students, we started a project. Forty honours students and honours alumni from eleven different universities and eight of their teachers were interviewed about the development of their talents, why they participated in an honours programme and what their experiences were in those programmes (Van Eijl \& Pilot, 2016). These interviews gave an in-depth picture of students' honours experiences and thereby gave insight into the process of talent development. This process is represented by the Circle of Talent Development. In the second part of this paper (step 9b of the Circle) we focus on the use of honours as laboratory for 21st century skills and the dilemma of teachers between "control and letting go" are discussed.

\section{What do we mean by talent?}

Before we go deeper into talent development, we consider the question of what we mean in this project with talent. When we talk about talent, we mean "qualities" anyone has that can be further developed and can lead to exceptional results and outstanding performance.

These qualities can relate to many domains. In education, students can achieve good results in a particular domain, both in practical ("they have golden hands") and theoretical ("they have brains") terms. For example, they can learn to work very systematically or learn to recognize and use their creativity. Furthermore, an individual can develop further in communication, problem solving and teamwork skills. Sometimes students in an honours programme discover the importance of taking the initiative and seizing opportunities. 
Some of these qualities are also called 21st century skills, because it is expected that graduates need those skills in this century. The following quote from Ton Peeters, coordinator of the honours programme Biology (Utrecht University), already gives an idea of the development of 21st century skills in an honours programme: 'The honours programme stimulated a group of students to write a book together. It is important that they are responsible for the whole process, from the initial brainstorming to the final publication. They are creative, they work together and are critical about themselves, each other and about the product. Students in this setting have ownership of their learning: it works better than when a teacher dictates what and how to learn. The fun of learning is many times greater' (Ton Peeters, lecturer and teaching fellow, 21st century skills, Utrecht University, 2014). Analysis of the interviews showed striking similarities with 21st century skills, such as opportunity recognition, benefit from multiple perspectives, multidisciplinary collaboration, creative and innovative thinking, solving complex multidisciplinary issues and intercultural skills.

\section{Outcomes of the interviews}

The interviews were collected and analysed. The analysis showed a wide variety of experiences of students in the honours programme; both students and honours programmes differed. We identified patterns in the answers of students in connection with themes from literature. These patterns were organised in "the Circle of Talent Development" (see figure 1).

Figure 1: The ten steps into the Circle of Talent Development

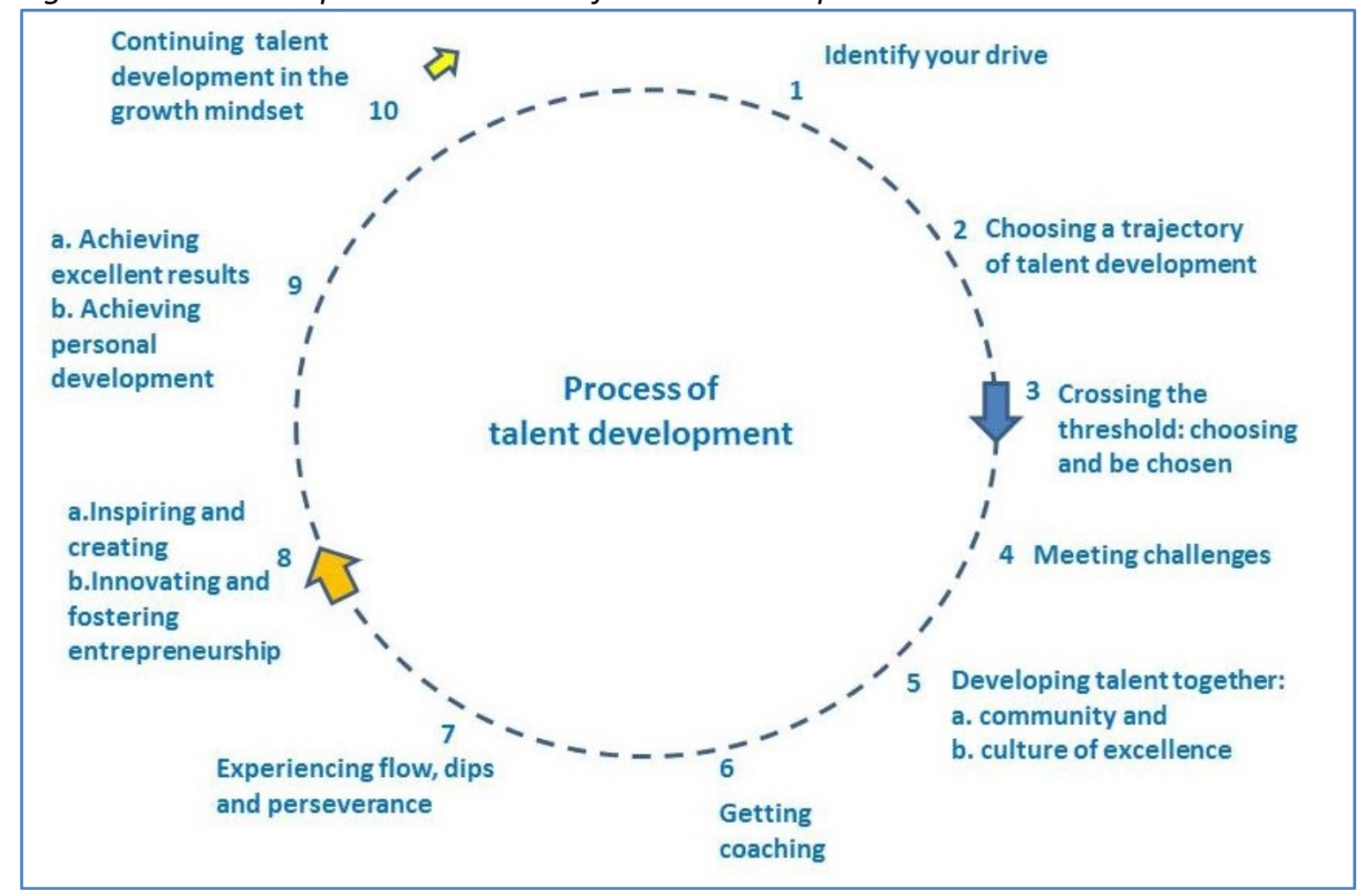

We also identified ideas and tips for talent development in honours programmes and other programmes. A series of similarities of honours experiences with 21 st century skills were noted. 
A book was written of the outcomes of this project and workshops were carried out. The book was written for both students and teachers and is available for everybody in the Dutch language with a synopsis in English (Van Eijl \& Pilot, 2016).

\section{The Circle of Talent Development}

The process of talent development in an honours programme is key in the outcomes of the interviews. This process has several steps, from the start to the completion of the honours programme and beyond. Not every student goes through these steps in the same order, but they are often revealed in the interviews. For clarity, we have therefore arranged the steps in the "Circle of Talent Development" (see Figure 1), which was partly inspired by "The hero's journey", a book of the well-known anthropologist Joseph Campbell (1949).

We first describe the steps in the circle and illustrate them with brief quotes from students' interviews.

\section{Step 1: Identifying your drive}

The start of the process of talent is shown in Step 1: identifying your own passion and drive; the students identify what they want to do more than their regular curriculum provides. An example: 'Looking for a little extra, a chance I could grab to distinguish myself from the rest' (honours student Amsterdam UAS). Sometimes it is not only doing more but also doing study activities in a different way, which gives the student an extra challenge. Some students are not yet aware of their talents but sometimes their teachers are. For these students with 'latent talent' (Verbiest \& Dijk, 2010), teacher intervention can help them to do the step for extra talent development.

\section{Step 2: Choosing a trajectory for talent development}

Students who need more challenges, look for new opportunities. Following an honours programme is an opportunity that comes on the student's path. An example: 'Do not stop and go for your dreams, because these efforts will be recognized and so you will always produce something' (honours student Saxion UAS). One way in which a student can get acquainted with an honours programme is to get information from a student who is already an honours student. Some schools ask honours students as ambassadors for the programmes, and ask them to provide information to their fellow students. The choice to participate in an honours programme may be a part of the development of a student's personal leadership. This is the ability to make decisions that impact their lives in a positive way.

\section{Step 3: Crossing the threshold: choosing and being chosen}

The choice to participate in an honours programme must come from both sides: the student must choose, but the teachers of the honours programme must also allow the student to be admitted, students must meet the selection criteria. They often have to write a motivation letter and sometimes there is an admission interview. An example: 'Finally, I was invited to an admission interview' (honours student Windesheim UAS). The teachers also consider the study results and consider especially whether the student is really interested in the honours programme, has a proactive attitude and a capacity for growth. Sometimes the principle of 'giving and taking' plays a part: both the teacher and the student are expected to contribute actively. At Utrecht UAS students sometimes have to write a proposal for their honours track. An honours teacher decides about the quality and feasibility of the proposal, and if it is 
good, the student can start. No high grades as selection criteria but the quality of their idea. This is an alternative way of selection (see step 4 about students that can bring in their own projects).

\section{Step 4: Meeting Challenges}

Once in the honours programme, the challenge and the actual learning really start. Students get complex, authentic assignments and projects (see figure 2) that are often linked to real (societal) problems and real clients. Sometimes students can bring in an own project.

\section{Figure 2: Students in an honours project}

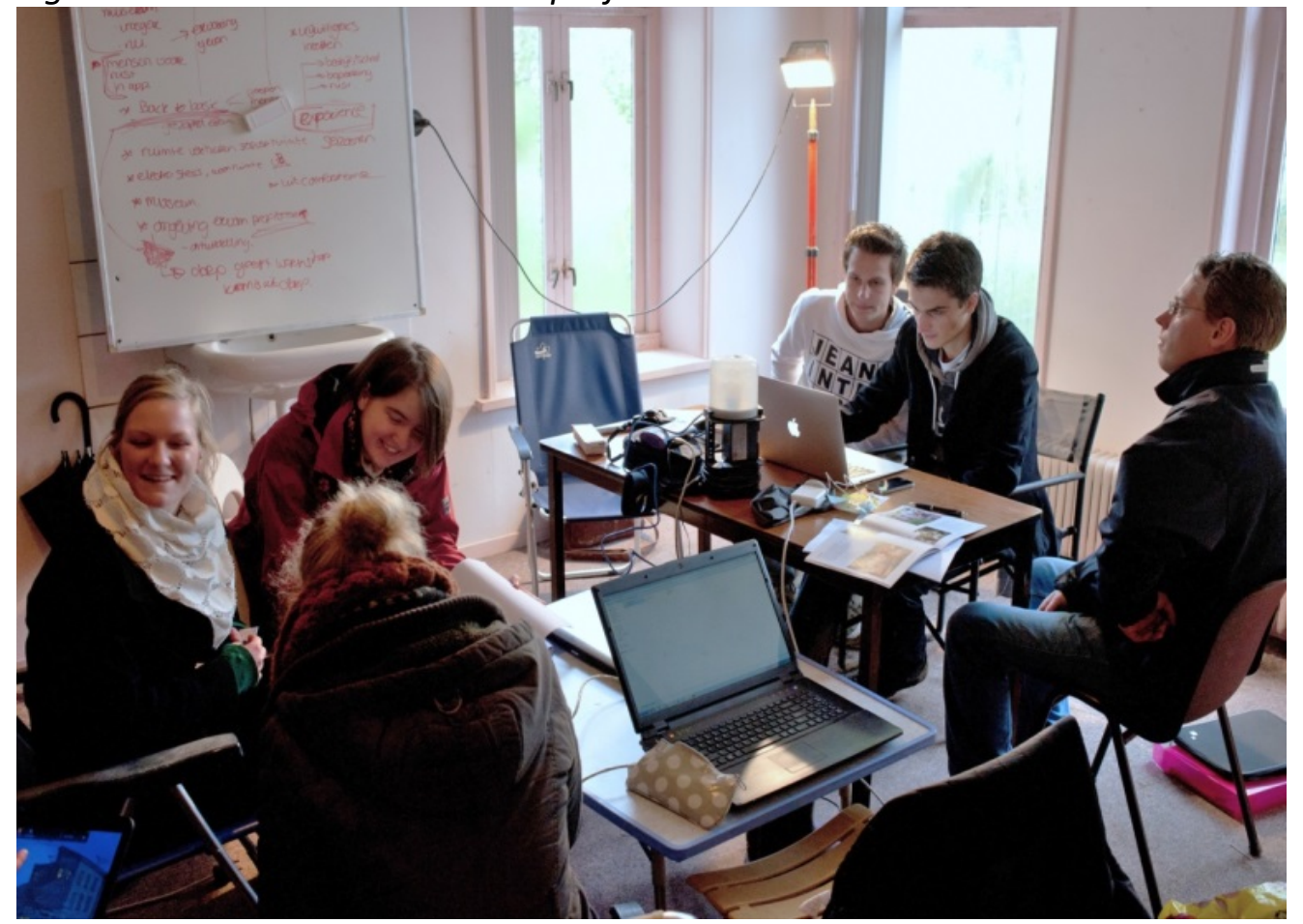

Photo: Hems Zwier, Windesheim University of Applied Sciences, http://www.hemszwier.nl/Hems Zwier.html

An example: 'We had a lot of guest lectures, which were not all equally interesting. But then came the team assignment for the police organisation and that was really cool' (honours student Windesheim UAS). In the honours programme students sometimes work together with students from other disciplines, teachers or even external clients. This differs from the approach in mainstream education and provides a challenge for the student and the supervisor. The teacher must include dealing with the differences between students and this may pose dilemmas for the teacher as well.

\section{Step 5a, b: Developing talent together in a community and culture of excellence}

Most students study not only individually but together with other motivated students and usually are remarkably positive about this in the honours programme. By working together, they come to an exchange of new ideas, give each other feedback, coach each other and stimulate their personal development. An example: 'The way we work and the atmosphere within the honours programme are worlds apart from the regular education' (honours student Windesheim UAS). The networks of contacts within the programme often grow into an 'honours community'. In the interviews many students speak with great appreciation 
about their community. A characteristic of these communities is the culture of excellence: encouraging each other, working together and achieving a result that matters!

\section{Step 6: Getting coaching}

Coaching can make the difference in talent development. The teacher can help a student to get on track and ensure that his or her talent development is really successful. To achieve this, the coach helps the student to get out of his or her comfort zone and enter into the 'zone of proximal development', thus doing new activities. An example: 'The coaches did not tell us what to do, but they encouraged us to make our own decisions and to develop ourselves. If necessary, we could always consult the coaches. Because I got a lot of freedom I worked more focused' (honours student Amsterdam UAS).

\section{Step 7: Experiencing flow, dips and perseverance}

An important experience in the talent development process is to get the feeling of 'flow': everything seems to go without saying, and the student is studying in an optimal state of development. An example: 'Almost the entire period of the honours programme it felt like a flow! In the beginning however I had some anxiety whether I would be able to handle this programme' (honours student Utrecht UAS). But dips may also occur, which may constitute a serious obstacle. The identification of a dip and overcoming these dips, requires resilience and perseverance. Learning to identify and overcome a dip is considered an important learning experience by these students.

\section{Step 8a: Inspiring and Creating}

Some assignments require new solutions, for which creativity is important. The use of one's own creative ideas and moments of inspiration is important to progress. Courage is indispensable for creativity to flourish! Aspects of the creative process, such as problem finding, the design challenge and fostering a creative atmosphere are important. But if new ideas are put forward not everyone will be positive, so students have to learn to deal with 'resistance to change'. An example: 'Everyone has ideas, but you should be able to explain exactly what this entails, even to people from other disciplines who do not immediately see the benefit of a product' (honours student Utrecht UAS).

\section{Step 8b: Innovating and entrepreneurship}

Some ideas can be turned into something that has concrete practical value: an innovation. An example: "In the "Future Search course" I was part of a group developing an app that was related to injury prevention in sports' (honours student Utrecht UAS). In this honours course the process of developing an innovation is discussed. The aim is to generate new ideas and to convert these into something that is relevant in practice; it requires entrepreneurial behaviour of students. As an example Vincent Gelink, an honours alumnus, gives his view on innovation in boxed text 1. 
In many situations in our lives we meet challenges that we have to overcome. These challenges can be found in several aspects of our lives. It is good to understand that not every challenge will lead to innovation. The challenges that lead to innovation are mostly based on a situation that irritates or where one starts thinking 'there must be an easier way to do this'. That moment can be the start to think about new ways to handle the same situation and a stimulant to start combining knowledge already present. This can lead to the realisation of something new, or as we would say: 'innovation'.

\section{Learning how to innovate}

Having a new idea or a new combination of existing ideas isn't immediately a new business with which one can make a living. The question about 'How to develop your idea into a service or product' will be the start of your journey of owning a scalable business. During this journey you will learn different lessons about entrepreneurship and what you need to do to keep your business alive. This process is part of learning how to innovate. Every step in your journey and business should help you make it better, more effective or easier to use for the user/buyer. At the end of this process you can start thinking about your own start-up.

\section{Start-ups}

Nowadays everybody knows the term start-up. A start-up is a company that is in the starting phase of its existence, therefore it has limited resources. In this phase, the owner of the start-up is still gathering information for the company and learning how to run, expose and develop its business. Most entrepreneurs know tools that can be used during this phase, such as the canvas business model (Osterwalder \& Pigneur, 2009), the golden circle (Sinek, 2009) and many others. With these tools they determine if the start-up has a chance to make it. They will also analyse their prospective market position, through for instance the blue and red ocean analogy (Kim \& Mauborgne, 1997). When your company is in the red ocean the competition is great and you are doing something that other companies are doing as well. If you are operating in the blue ocean you are more unique and more likely an innovative entrepreneur as there are few businesses that provide a similar service or product or have a similar business proposition. The combination of business and innovation can have many different forms and strategies. Two types of innovation that have impact on society and the existing market, are discussed here.

\section{Social innovation}

Social innovation is addressing a societal problem and deciding to do something about it. Because it often concerns several levels of society it can grow rapidly and combine a broad set of possibilities. For instance you can think of a company that works with self-employed workers and volunteers to develop a certain solution for a local issue. In the end, society benefits the most from social innovation. For a start-up this can be a real game changer. Because a diverse group is experiencing the same situation which can yield a possibility to expand your resources. By working together with companies, the government and other institutions on a national or international basis one can accelerate the growth of their business and expand their network.

\section{Disruptive innovation}

Disruptive innovation is more focused on changing the standard that companies are used to. It can be a threat to existing companies and their market. The start-ups that makes it to be a 'disrupter' are known by almost everyone like Tesla and Airbnb. But comparing the real disrupters to the actual market, there are only a few who made a difference. Disruption is hard to accomplish but it can give you a platform to change the way business 'is' to how you envision it should be.

\section{Step 9a: Achieving excellent results}

Efforts in an honours programme can lead to excellent performance. When and in what ways is an achievement excellent? An example: 'I definitely feel I have delivered an excellent performance. When I look at my thesis, it contains all five honours competencies of Rotterdam UAS' (honours student Rotterdam UAS). The contribution of students to organizing the programme and producing products for external clients can be part of these 'excellent' achievements. 


\section{Step 9b: Achieving personal development}

Equally important is the personal development that was often mentioned by the interviewed students. An example: 'There is a lot of freedom allowing you much more to come to personal development, because there is much room to get to know yourself and figure out how you learn best' (honours student Saxion UAS). Personal development skills are about knowing yourself and your relation to the other and the world around you and what kind of meaning you want to have for the world around you. These skills are also mentioned as important in so-called 21st century skills (see $D$ in boxed text 2 ).

\section{Boxed text 2. Honours programmes provide inspiring examples for teaching 21st century skills}

During interviews with honours students we typically found learning experiences such as meeting challenges, developing innovative initiatives, crossing borders and adopting a proactive stance. We can identify many of these experiences as the development of 21 st century skills. These are the skills that would be expected to become more important in the course of the 21st century. An international team of researchers have formulated these 21st century skills especially for use in primary and secondary education in the KSAVE model (Knowledge, Skills, Attitudes, Values and Ethics) (Binkley et al, 2010). A model that was further developed in the Netherlands by Boswinkel and Schram (2011). Four groups of skills are formulated:

(A) methods of thinking;

(B) methods of working;

(C) instrumental skills; and

(D) citizenship and personal development.

In each group a number of skills is identified.

In the interviews with honours students, these 21st century skills from the KSAVE-model were repeatedly mentioned. The multidisciplinary work (D) for example, is often mentioned as important, which means that a group of students (B) of several different disciplines tries to tackle a problem by using knowledge and skills from different disciplines. This often leads to unique solutions. In this way students will develop a multidisciplinary frame of reference and often also an international and multicultural orientation (D). The teamwork and the culture of excellence in an honours programme can give the development of other 21st century skills a huge boost. An honours student says she missed this stimulant in her regular programme: 'If you miss the academic challenge in your studies, then an honours programme is incredibly valuable. Because you are surrounded by people who have a similar mentality, you also get additional energy to develop yourself and to get the best out of yourself. This honours climate I missed in my regular programme.'

ICT (B and $C$ ) is an increasingly important tool which is reflected in all facets of society and business. This trend will only continue to go out and this means that it is a must for an honors student with ICT to cope in the 21st century. It turned out in the interviews that the use of ICT seems self-evident for the students in the honours programmes, but it should be noted that new ICT applications like digital intelligence, robotics and big data are continuously being developed and influence disruptively the labour market for graduates

Writing and presentation skills (B) have an important place in honours programmes, however these may get a new and contemporary face, for example in the form of an elevator pitch, virtual reality or exposure live or on the internet.

Some honours programmes stimulate opportunity recognition (D). This is the recognition of an entrepreneurial challenge, a creation or a discovery of something new which may have value for potential clients or society and which may generate revenue for the entrepreneur.

\section{Step 10: Continuing talent development in the growth mindset}

If a project or task is completed within an honours programme, then a new project starts, which again, follows (parts of) the Circle of Talent Development. This relates in particular to step 4 to 9 of this circle. Talent development does not simply stop after the honours programme, but grows into a 'way of life' as the honours alumnus continues to develop himself or herself. An example: 'The honours programme has had great influence on my further study and work. I decided, instead of immediately going to work and to start with a 
house and garden, to first search for more adventures' (honours student Utrecht UAS). To identify opportunities for growth and to address a growth mindset is important. Ninib Dibo, honours alumnus gives his view on this topic in boxed text 3.

\section{Boxed text 3. The growth mindset, challenge yourself after the honours programme, a view from honours alumnus Ninib Dibo}

Stanford professor Carol Dweck (2015) did extensive research about mindsets of children and students in relation to their development. An individual with a growth mindset believes that talent and abilities can be improved and developed upon. The antithesis of this being a fixed mindset, where one believes talents and abilities are fixed or cannot be changed. An individual student does not need to hold one of the extreme views, both mindsets can appear to a greater or lesser extent within a single individual. For example, a student might believe that he will never be able to play the piano because he simply lacks the talent while simultaneously this student believes that he can improve his understanding of neurology through effort and study.

The flexibility the growth mindset suggests, may correlate with neuroplasticity. This is a term used in neurology to describe the fact that our brains are capable of constant change throughout our entire life. Learning can result in anatomical changes in the brain (Draganski, Gaser, Busch, Schuierer, Bogdahn \& May, 2015) as new connections between brain cells (neurons) are made in order to adapt to the new demands of one's environment. The very idea suggests that after reading this text intensively and repeatedly applying its content, your brain will have changed, creating new neural connections as a response to processing new information.

Honours programme, a growth mindset and what comes after

Honours programmes apply the idea of a growth mind set, as can be seen through the application of the Circle of Talent Development. Self-development stands at the very core of honours programmes including the idea that this development is a constant, never-ending process. As long as one is willing to learn, he or she will be able to improve. The environment created during honours programmes is essential for this learning process. Honours programmes allow one to make mistakes in the understanding that it is part of the learning process. You are allowed to search for what inspires you and learn through theory as well as trial and error. In other words: 'Learn from failure, don't be afraid!' Developing oneself after the honours programme might require you to recreate this philosophy to a greater extent in your professional and personal life. It may ask you to search for environments that allow for talent development. There are career programmes such as traineeships that, just like honours programmes, understand that an individual must learn many new skills in order to function optimally. These programmes allow you the tools and time to find out what inspires you, find your passion and pursue it within the organisation involved. Such traineeships also understand that one must sometimes learn from failure, that learning is a constant process and that those who follow their passion are more likely to go above and beyond expectations to deliver excellent results. The drive to be better than you were yesterday is what truly shows the honours mind set.

\section{The teacher and the Circle of Talent Development}

For the student activities in the Circle of Talent Development teachers are of great importance (Wolfensberger, 2012). Different student activities in the Circle of Talent Development require different teaching activities. Teachers are the ones who design the activities in the honours programme, often in co-creation with the students, and create opportunities for the students to achieve the required talent development, without 'setting plans in stone'. They are also the ones who guide the student, encourage them, give them feedback and review them. There is need for the preparation of the honours teacher. In an interview, Ron Weerheijm, coordinator of the honours programme at Rotterdam University of Applied Sciences, said that he therefore requires new teachers to make a scenario in advance: 'What could happen and what should I be prepared for? Otherwise, the teacher falls back on old teaching behaviour and the dynamism of talent development is lost. The teacher must be prepared for the problems he may encounter.' In addition, in various universities nowadays courses on honours teaching are organized for new honours teachers. Attention is paid to both the design, the intervention in the process of talent development 
and evaluation of honours programmes (see for example Coppoolse et al., 2013, p. 127). A focal point in the design of an honours programme and the guidance of students is the tension between 'control' and 'letting go', see boxed text 4.

\section{Boxed text 4. Teachers dilemma: balance between "control" and "letting go"}

One of the interviewed teachers said that this dilemma was 'the most difficult question for me in the honours teaching'. To be more specific: the dilemma between the aims and structure of the programme and the diverse goals of individual students (see also Scager, Akkerman, Pilot \& Wubbels, 2016). Teachers and students gave examples for both sides of this dilemma in the interviews. For example a teacher: 'The teacher creates space for the students and facilitates the process in order to come up with new ideas.' Another teacher: 'It is a challenge for teachers, to allow students to explore their passion.' A student: 'The special thing about this programme is that you get much freedom to propose projects yourself. The programme is largely determined by your own creativity and assertiveness.'

Another teacher brought up his role in coping with the dilemma: 'In the honours programme, I am a facilitator, and constantly try to bring the students into the zone of proximal individual development.'

This zone of proximal development (Vygotsky, 1978, 1934) has been visualized in figure 3.

\section{Figure 3: Coaching in the zone of proximal development}

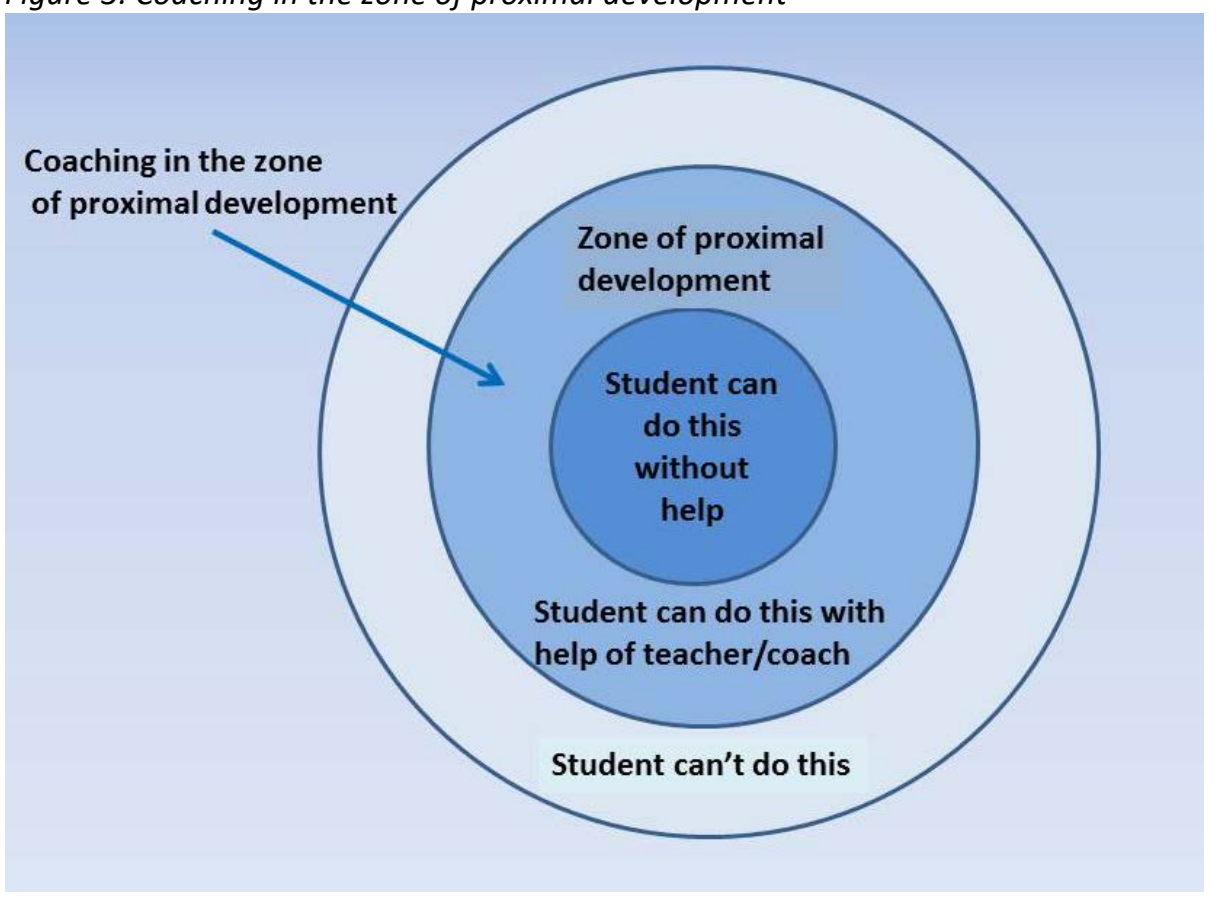

The zone of proximal development refers to challenges that are so new for a student that he or she needs some form of coaching to find his or her way. About this coaching role a student says: 'The coaching was primarily to support. There was a lot of room for your own initiatives and discussion. In the honours programme there is much freedom for your own projects and approaches.' Another student: 'The coaches did not tell us what to do, but they encouraged us to make our own decisions and develop our ideas.' A teacher emphasizes how different the coaching role is from the teaching role: 'As teachers we have the idea that we can control the learning process and the outcomes to a large extent, but that is a misconception, I think. Facilitating is really different from controlling and organising.'

The freedom that is often present in honours programmes, may also lead to more personal development for the student: 'There is a lot of freedom allowing you to come to personal development, because there is much room to get to know yourself and figure out how you learn best.' However, a lot of freedom may also be a problem for an honours student: 'The freedom and independence also have a downside. Many, including myself, didn't know what we had to do, during our first year.' A teacher has experienced that 'a number of new honours students have to get used to their new freedom and the uncertainty that comes with this freedom.' 


\section{Key points of the Circle of Talent Development}

We can summarize the essence of the Circle of Talent Development with a few statements:

- Talent development begins by addressing a challenge (a long term goal) and is continued in working persistently on that challenge (grit; see Duckworth, 2016).

- Talent development requires not only individual study but also exchange with others. Social interaction with fellow students and coaches provides inspiring input to develop new perspectives and insights.

- Opting for talent development is entering into an adventure of which the outcome is still uncertain. This asks much from a student's proactivity, dedication and ingenuity and often leads to unusual and surprising results.

- The process of talent development is, for most students, not only a flow experience but also requires hard work, perseverance and overcoming dips. Overcoming a dip however can be a major learning experience.

- The learning experience of many honours students refers not only to content but involves also a major gain in personal development.

- Honours programmes offer many opportunities to acquire 21st century skills.

- Teachers have to find a balance between 'control' and 'letting go' and coaching is, in this respect, considered an important task for honours teachers.

\section{References}

Binkley, M., Erstad, O., Herman, J., Raizen, S., Ripley, M. \& Rumble, M. (2010). Defining 21st century skills. Melbourne: University of Melbourne.

Boswinkel, N. \& Schram, E. (2011). De toekomst telt. Enschede: SLO/Ververs Foundation.

Campbell, J. (1949). The hero with a thousand faces. 1st edition, Bollingen Foundation, 1949. 2nd edition, Princeton University Press. 3rd edition, New World Library, 2008.

Coppoolse, R., Eijl, P.J. van \& Pilot, A. (2013) Hoogvliegers, ontwikkeling naar professionele excellentie. [High flyers, development towards professional excellence]. Rotterdam University Press. English synopsis: https://www.researchgate.net/profile/Pi Eij//contributions Dutch full text: http://hr.surfsharekit.nl:8080/get/smpid:60567/DS3/

Draganski, B., Gaser, C., Busch, V., Schuierer, G., Bogdahn, U. \& May, A. (2004). Neuroplasticity: Changes in grey matter induced by training. Nature 427, 311-312 (22 January 2004). doi:10.1038/427311a

Duckworth, A. (2016). Grit. Amsterdam: Bruna.

Dweck, C. (2015). Carol Dweck revisits the 'Growth Mindset'. Education week. http://www.islandtrees.org/main/curriculum/rgm.pdf

Eijl, P.J. van, \& Pilot, A. (Eds.) (2016). The Honours Experience, talentontwikkeling door de ogen van de honoursstudent. [The honours experience, talent development through the eyes of honours students] Rotterdam: Hogeschool Rotterdam Uitgeverij 
English synopsis: https://www.researchgate.net/profile/Pj_Eijl/contributions

Dutch full text: http://hr.surfsharekit.nl:8080/get/smpid:61232/DS1

Eijl, P.J. van, Pilot, A. \& Wolfensberger, M.V.C. (2010). Talent voor morgen, ontwikkeling van talent in het hoger onderwijs [Talent for tomorrow, development of talent in higher education]. Noordhoff Uitgevers.

Kim, W.C., \& Mauborgne, R. (2015). Blue Ocean Strategy, Expanded Edition: How to Create Uncontested Market Space and Make the Competition Irrelevant. Boston: Harvard Business School Press.

Osterwalder, A., \& Pigneur, Y. (2009). Business model generation: a handbook for visionaries, game changers, and challengers. John Wiley \& Sons.

Peeters, T. (2014). Teaching fellow Ton Peeters bereidt studenten voor op onvoorspelbare arbeidsmarkt (interview). DUB (Digitaal Universiteitsblad Universiteit Utrecht) 24 oktober 2014. Retrieved from: http://www.dub.uu.nl/artikel/achtergrond/teaching-fellow-tonpeeters-bereidt-studenten-voor-op-onvoorspelbare.html

Scager, K., Akkerman, S.F, Pilot, A. \& Wubbels, T. (2016). Teacher Dilemma's in challenging high-ability students in higher education. Teaching in Higher Education. DOI:

10.1080/13562517.2016.1248392.

Sinek, S. (2009). Start With Why - How Great Leaders Inspire Everyone to Take Action. USA: Penguin Group.

Verbiest, C. \& Dijk, M. (2010). Oog voor talent. [An eye for talent]. Amersfoort: CPS

Vygotsky, L.S. $(1978,1934)$. Mind and Society: The development of higher psychological processes. Cambridge, MA: Harvard University Press.

Wolfensberger, M.V.C. (2012) Teaching for excellence. Honours Pedagogies revealed (PhD thesis). Münster, Germany: Waxmann. 